\title{
Análise das forças produzidas por alças de nivelamento: ensaio mecânico
}

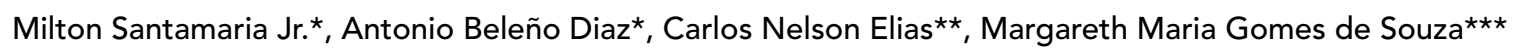

\section{Resumo}

Objetivo: avaliar a força aplicada pelas alças simples, L divergente e L convergente, confeccionadas no fio de 0,016 polegadas, durante a fase de nivelamento, em função da deformação produzida e da amarração do ômega na extremidade posterior dos arcos. Metodologia: empregou-se um modelo especialmente construído para o experimento, mensurando-se as forças por meio da máquina universal EMIC-DL10.000. Resultados e Conclusões: a deformação produzida variou de 0,5 a $2 \mathrm{~mm}$ e gerou força que variou de 75,1 a $268,5 \mathrm{gf}$ para alça simples, 69,7 a 24l,0gf para a alça L divergente e 67,0 a 220,4gf para a alça L convergente, na condição de não se amarrar o ômega. Quando o ômega foi amarrado ao molar, a força variou de 105,0 a 311,6gf; 70,8 a 251,4gf e 69,4 a 243,4gf; respectivamente. Aplicou-se teste $t$ de Student para variáveis pareadas e foi verificado que a alça simples produziu maior força de acordo com a deformação, seguida da alça $L$ divergente e $L$ convergente $(p<0,05)$. Esta força cresce ainda mais quando se amarra o ômega na extremidade posterior do arco nos três tipos de alças estudadas $(\mathrm{p}<0,05)$.

Palavras-chave: Alças. Nivelamento. Extrusão.

\section{INTRODUÇÃO}

No início do século passado Angle idealizou um arco rígido (Arco "E"), que passava pela vestibular dos dentes com função de ancoragem para o tracionamento dos mesmos em direção ao arco. Este procedimento tinha o objetivo de alinhar os dentes e estabelecer a correta forma do arco dentário.

Angle, na década de 1930, após contínuas mudanças em seus aparelhos, desenvolveu braquetes e tubos melhorando o controle tridimensional do movimento dentário, facilitando o alinhamento e nivelamento. Esta técnica ficou conhecida como
Edgewise ou arco de canto. Muitas foram as inovações e melhorias introduzidas, mas, sem dúvida, os princípios mecânicos desenvolvidos principalmente por Angle ${ }^{1}$ na técnica Edgewise perduram até os dias de hoje.

Tweed $^{10}$ incorporou na técnica Edgewise alças utilizadas na técnica de Begg², com objetivo de aumentar a flexibilidade do fio durante o alinhamento e nivelamento, produzindo forças mais suaves, menos danosas para os tecidos periodontais.

Nos últimos 70 anos, o conceito de força ótima foi estudado exaustivamente. Schwarz ${ }^{9}$ propôs o

* Mestre em Ortodontia pela FOUFRJ

** Professor Adjunto da Universidade Federal Fluminense e Instituto Militar de Engenharia.

*** Professor Adjunto da Disciplina de Ortodontia da FOUFRJ. 
conceito clássico de força ótima onde a força liberada para remodelar os tecidos ósseos deve ser semelhante à pressão dos capilares ${ }^{9}$. Desta forma, forças excessivas causariam a obliteração dos vasos e conseqüente necrose dos tecidos, impedindo a reabsorção óssea frontal. Reitan ${ }^{8}$, em seus estudos histológicos sobre movimentação dentária, confirmou os estudos de Schwarz ${ }^{9}$ verificando as áreas hialinas, a ausência de células no lado de pressão, concluindo que forças leves deveriam ser aplicadas aos dentes durante sua movimentação.

Infelizmente, não é fácil determinar qual é a força ideal para a movimentação de um dente, pois muitos fatores estão envolvidos, como o tipo de força, se contínua ou intermitente, a área radicular do dente a ser movimentado e a própria variação biológica individual dos pacientes. De qualquer forma, durante a aplicação de uma força deve-se buscar sempre o maior movimento dentário, com o menor prejuízo para os tecidos de suporte e o maior conforto para o paciente ${ }^{7}$.

Este trabalho teve como objetivo avaliar as forças produzidas por fios de aço inoxidável de calibre 0,016 polegadas deformados com diferentes formas de alças de nivelamento.

\section{MATERIAL E MÉTODO}

Tomando como modelo experimental a arcada superior de um paciente que realizou tratamento ortodôntico na clínica de Ortodontia do Programa de Pós-Graduação da FOUFRJ, foi obtida a impressão do arco superior com hidrocolóide irreversível do tipo alginato. Nesta impressão confeccionou-se um modelo com resina acrílica autopolimerizável, onde braquetes da marca Morelli ${ }^{\circledR}$ foram devidamente posicionados e colados.

A seguir, seccionou-se o incisivo central superior esquerdo, deixando-o livre para movimentação. A loja contendo este elemento no modelo media $7 \mathrm{~mm}$ de comprimento por $12 \mathrm{~mm}$ de altura e, para assegurar a este bloco um movimento totalmente livre de qualquer atrito, margens de segurança foram estabelecidas nas superfícies distal e mesial medindo cerca de $1 \mathrm{~mm}$ e na apical cerca de $3 \mathrm{~mm}$. $\mathrm{Na}$ face incisal do incisivo central superior esquerdo, que foi movimentado, um fio de aço de $0,9 \mathrm{~mm}$ de diâmetro e $20 \mathrm{~mm}$ de comprimento com ranhuras na sua extremidade livre foi fixado ao dente, servindo de apoio para o ensaio mecânico (Fig. 1).

Três tipos de alças de nivelamento foram utilizadas para o ensaio mecânico (Fig. 2), no qual determinou-se a força produzida por alças simples, L convergente e $\mathrm{L}$ divergente na simulação para induzir o movimento de extrusão de $0,5 \mathrm{~mm}$, $1 \mathrm{~mm}, 1,5 \mathrm{~mm}$ e $2 \mathrm{~mm}$.

As alças foram padronizadas por meio de um template desenhado em papel milimetrado. Confeccionou-se 5 alças de cada tipo com fio de aço 0,016 polegadas, de secção redonda. Estes fios contendo as alças foram conformados em parábolas com distância intercaninos de $22 \mathrm{~mm}$, compatível com o modelo da arcada dentária utilizada no experimento. Foram confeccionados ômegas na extremidade posterior destes arcos, justos à mesial do último molar da arcada de ambos os lados. Os arcos foram amarrados aos braquetes por meio de ligaduras elásticas, onde se mediu a força

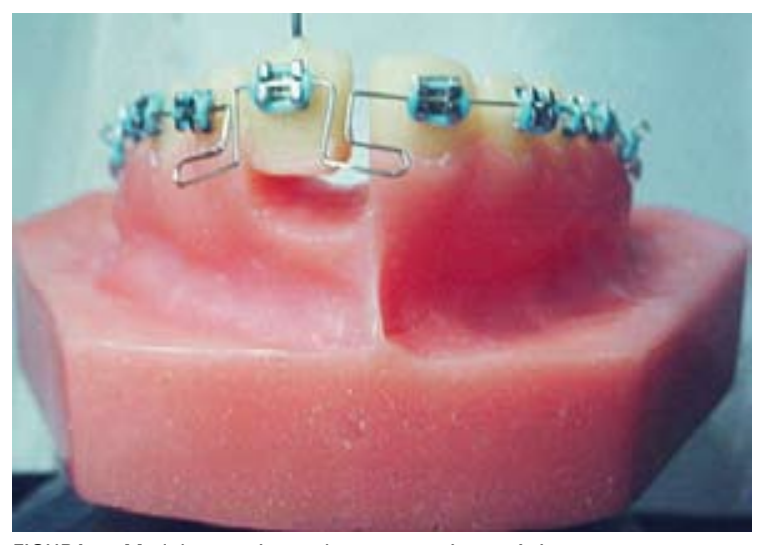

FIGURA 1 - Modelo experimental para o ensaio mecânico.

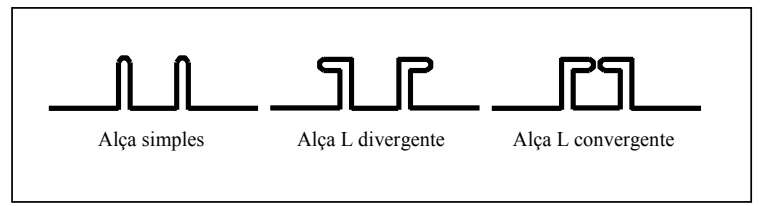

FIGURA 2 - Desenho das alças utilizadas no experimento. 
de acordo com a deformação produzida no fio durante o movimento simulado de extrusão, avaliando-se as variáveis: 1) tipo de alça e 2) amarração ou não do ômega dos arcos com amarrilho metálico.

Nos ensaios mecânicos, realizados no Instituto Militar de Engenharia - IME-RJ, empregou-se a máquina de ensaios mecânicos EMIC-DL10.000 acoplada a um microcomputador, a qual forneceu para cada fio testado um gráfico força $\mathrm{x}$ deformação.

\section{ANÁLISE ESTATÍSTICA}

Os resultados obtidos foram submetidos à análise estatística determinando-se os valores médios, desvio padrão e significância estatística (valor p). Os valores médios entre os grupos foram comparados por meio do teste $t$ de Student para variáveis pareadas.

\section{RESULTADOS}

As forças produzidas em função do movimento de extrusão, empregando-se as diferentes alças sem amarrar o ômega, são apresentadas na tabela 1 .
Pode-se observar que a alça simples produziu a maior força em todas as amplitudes de deformação, seguida pela alça do tipo L divergente e L convergente, respectivamente. Estes resultados foram estatisticamente significantes com $\mathrm{p}<0,05$.

Mostra-se, no gráfico 1, a curva representativa dos ensaios mecânicos para as diferentes alças. Pode-se observar que, de modo geral, para todas as alças, ocorreu aumento significativo da força até a deformação de $1,5 \mathrm{~mm}$ e a partir deste valor o incremento da força foi menor, se estabilizando na amplitude de extrusão de $2 \mathrm{~mm}$. $\mathrm{Na}$ deformação de até $2 \mathrm{~mm}$ todas as alças foram submetidas ao carregamento em seus regimes elásticos.

$\mathrm{Na}$ segunda fase dos ensaios mecânicos as alças foram submetidas novamente à mesma deformação, porém amarrando-se no tubo do último molar o ômega confeccionado no fio. Os resultados desta série de ensaios mecânicos são mostrados também na tabela 1 .

Pode-se observar grande diferença nas forças produzidas pelos três tipos de alça. A alça simples

Tabela 1 - Média e desvio padrão das forças produzidas pelas alças (gramaforça) em função da deformação (milímetros) sem amarrar e amarrando o ômega.

\begin{tabular}{|c|c|c|c|c|c|c|c|c|}
\hline \multirow[b]{2}{*}{ Alça Deformação } & \multicolumn{4}{|c|}{ Sem amarrar o ômega } & \multicolumn{4}{|c|}{ Amarrando o ômega } \\
\hline & 0,5 & 1,0 & 1,5 & 2,0 & 0,5 & 1,0 & 1,5 & 2,0 \\
\hline Simples & $75,1 \pm 7,4^{*}$ & $161,0 \pm 30^{*}$ & $265,2 \pm 62,6^{*}$ & $268,5 \pm 62,3^{*}$ & $105,0 \pm 37,4^{*}$ & $197,5 \pm 35,2^{*}$ & $306,8 \pm 61,4^{*}$ & $311,6 \pm 61,7^{*}$ \\
\hline L divergente & $69,7 \pm 7^{*}$ & $154,1 \pm 22^{*}$ & $237,3 \pm 34^{*}$ & $241,0 \pm 34,5^{*}$ & $70,8 \pm 10,4$ & $163,4 \pm 27,4$ & $241,2 \pm 51,1$ & $251,4 \pm 52,5$ \\
\hline L convergente & $67,0 \pm 9^{*}$ & $139,7 \pm 18,5^{*}$ & $217,0 \pm 32^{*}$ & $220,4 \pm 32,7^{*}$ & $69,4 \pm 6,5$ & $149,8 \pm 18,2$ & $239,0 \pm 39,8$ & $243,4 \pm 43,7$ \\
\hline
\end{tabular}

*- Diferença estatisticamente significante $-p<0,05$.

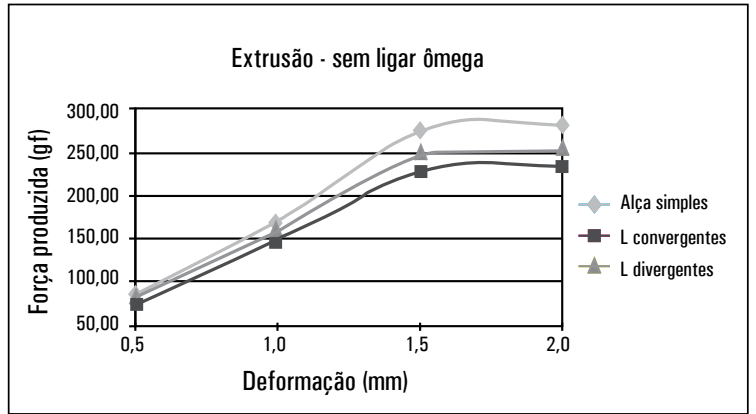

GRÁFICO 1 - Curva força $x$ deformação sem amarrar o ômega

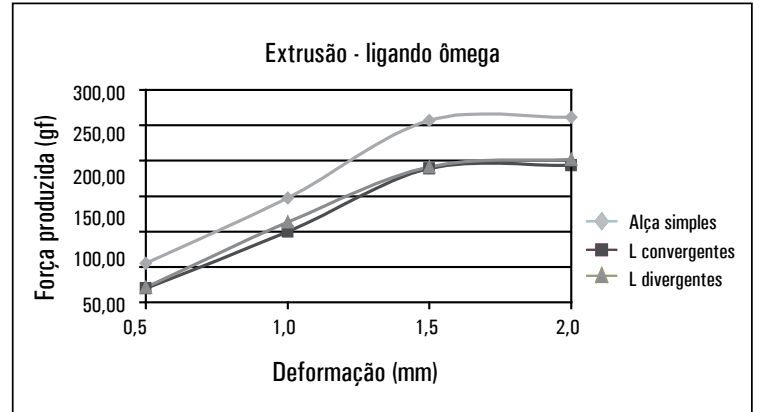

GRÁFICO 2 - Curva força $x$ deformação com o ômega amarrado. 
produziu a maior força quando comparada com as alças L divergente e L convergente e esta diferença foi estatisticamente significante $(p<0,05)$.

No gráfico 2 são mostradas curvas força $\mathrm{x}$ deformação para as três diferentes alças amarrando-se o ômega. Pode-se notar que as alças mantiveram o mesmo comportamento, onde com o aumento da deformação houve aumento da força, com estabilização após a deformação de $1,5 \mathrm{~mm}$. Neste caso, as alças também se mantiveram no regime elástico durante os ensaios de tracionamento.

De uma maneira geral, quando se amarrou o ômega na região posterior, teve-se uma força maior, exercida pelas alças durante a deformação do fio. Nas alças simples, o incremento da força foi bem maior (Gráf. 2).

\section{DISCUSSÃO}

O movimento dentário é resultado da aplicação de um sistema de forças e depende da resposta dos tecidos a esta força. Sobre o ponto de vista da configuração dos aparelhos ortodônticos, o sistema de forças é determinado pelas características do aparelho usado, como a conformação de alças, distância entre os braquetes e pelas características do fio. Diferentes ligas de metais podem ser usadas na fase de alinhamento e nivelamento, porém três propriedades para os fios constituem características importantes para o uso clínico: baixa rigidez, alta resiliência e baixo módulo de elasticidade ${ }^{3}$.

Devido à alta rigidez dos fios de aço inoxidável, na técnica Edgewise, deve-se iniciar o tratamento ortodôntico com fios de menor calibre, aumentando as dimensões gradativamente, tendo o cuidado sempre de se manter a forma da arcada dentária inicial, principalmente nos arcos confeccionados com fios de maior calibre. Em muitos casos, o desnivelamento dos dentes é muito grande nesta fase inicial do tratamento, sendo necessário fazer uso de artifícios que aumentem a flexibilidade do fio.

As alças foram preconizadas na técnica de Tweed ${ }^{10}$ e Begg $^{2}$ e têm o objetivo de aumentar o comprimento do fio existente entre dois acessórios, aumentando deste modo sua flexibilidade. Podemos empregar diferentes tipos de alças para diferentes procedimentos. Alças verticais simples (em U) fornecem elasticidade no sentido horizontal para o alinhamento, as alças em L possibilitam o movimento no sentido vertical e horizontal para o alinhamento e nivelamento.

Pode-se verificar que mesmo com a deformação em pequenas amplitudes de $0,5 \mathrm{~mm}$ e com o emprego de alças, forças maiores do que $70 \mathrm{gf}$ foram liberadas. Na deformação máxima de $2 \mathrm{~mm}$, forças de 268gf puderam ser verificadas, muito acima da forças biológicas recomendadas por Oppenheim ${ }^{6}$ e Reitan ${ }^{8}$. Estas forças devem ser na região de incisivos, segundo Jarabak e Fezzel1 ${ }^{4}$, por volta de 70gf, podendo resultar em seqüelas aos tecidos periodontais e pulpar, como relatado por Mostafa et al. ${ }^{5}$. Estes efeitos vão desde absorções da superfície radicular até o colapso circulatório com conseqüente necrose pulpar.

Observando-se os resultados obtidos neste trabalho (Gráf. 1, 2), deve-se reavaliar o uso de fios de calibre 0,016 polegadas em pequenas amplitudes de nivelamento das arcadas, mesmo com o emprego de alças. Nos casos onde o nivelamento exija deformação do fio maior que $0,5 \mathrm{~mm}$, artifícios como o aumento da distância entre os braquetes, a diminuição do calibre dos fios de aço inoxidável, mesmo com o uso de alças ou o emprego de fios com ligas mais resilientes, devem ser levados em consideração.

Em muitos casos, além do nivelamento, o profissional necessita amarrar o ômega na região posterior, evitando a projeção dos incisivos na região anterior. Nestes casos as forças exercidas pelas alças no nivelamento se tornam ainda mais críticas, onde a alça simples, mesmo com a ativação de apenas $0,5 \mathrm{~mm}$, exerce força maior que $100 \mathrm{gf}$, podendo chegar a mais de $300 \mathrm{gf}$ em uma ativação de $2 \mathrm{~mm}$, em apenas um elemento dentário.

Dentro deste contexto, o profissional deve buscar sempre recursos para evitar forças excessivas já na fase inicial de tratamento durante o nivelamento. 
A não observação desta premissa pode trazer efeitos deletérios e comprometer o tratamento como um todo, principalmente, em etapas posteriores que exigem a retração de incisivos onde a movimentação dentária é mais ampla.

\section{CONCLUSÕES}

- O uso de alças simples, L convergente e L divergente, quando conformadas no fio de aço inoxidável de diâmetro 0,016 polegada, durante a fase de alinhamento e nivelamento, pode liberar forças excessivas para os tecidos de suporte, principalmente quando a amplitude do movimento é maior ou igual a $0,5 \mathrm{~mm}$

- Quando o ômega não é amarrado ao tubo do último molar, a alça simples produz forças de 75,1 a 268,5gf de acordo com a deformação. As alças L divergente e $\mathrm{L}$ convergente produzem forças de 69,7 a 24l,0gf e 67,0 a 220,4gf, respectivamente.

- Quando o ômega é amarrado na mesial do último molar, apenas a alça simples tem um acréscimo de força estatisticamente significante onde a força na deformação mínima passa de 75,1 para 105,0gf e a força produzida na deformação máxima passa de 268,5 para 311,6 gf.

\title{
Analysis of the forces produced by loops: mechanical testing
}

\begin{abstract}
Aim: the aim of this work was to assess the force applied by the vertical loop, divergent boot loop and convergent boot loop, made with 0.016 " arch wire, during the leveling phase in function of the produced deformation and of the tie back in the posterior extremity of the arch wire. Methods: a special experimental model was built for this study, and a Universal Test Machine EMIC-DL10.000 was used to evaluate force levels. Results and Conclusions: The produced deformation varied of 0.5 to $2 \mathrm{~mm}$ and the force produced varied from 75.1 to $268.5 \mathrm{gf}$ for vertical loop, 69.7 to $241.0 \mathrm{gf}$ for the divergent boot loop and 67.0 to $220.4 \mathrm{gf}$ for the convergent boot loop, in the condition of not tying back the wire. When wire was tied back the force varied from 105.0 to $311.6 \mathrm{gf} ; 70.8$ to $251.4 \mathrm{gf}$ and 69.4 to $243.4 \mathrm{gf}$; respectively. It was applied Student $t$ test and it was verified that the vertical loop produces larger force in agreement with the deformation followed by the divergent boot loop and convergent boot loop $(p<0.05)$. This force is greater when the arch wire is tied back in the posterior extremity of the wire in the three types of studied loops $(p<0.05)$.
\end{abstract}

Key words: Loop. Leveling. Extrusion.

\section{REFERÊNCIAS}

1. ANGLE, E. H. The treatment of malocclusion of the teeth. 7th ed. Philadelphia: S. S. White, 1907.

2. BEGG, P. R.; KESLING, P. C. Begg orthodontic theory and technique. Philadelphia: WB Saunders, 1977.

3. BURSTONE, C. J. Beta titanium: A new orthodontic alloy. Am J Orthod, St. Louis, v. 77, no. 2, p. 121-132, Feb. 1980.

4. JARABAK, J. R.; FEZZELL, J. A. Technique and treatment with lightwire Edgewise appliances. 2nd ed. St. Louis: C.V. Mosby, 1972.

5. MOSTAFA, Y. A. et al. latrogenic pulpal reactions to orthodontic extrusion. Am J Othod Dentofacial Orthop, St. Louis, v. 99, no. 1, p. 30-34, Jan. 1991.

6. OPPENHEIM, A. Tissue changes, particulary of the bone incident to tooth movement. Am J Orthod, St. Louis, v. 3, no. 2, p. 57-67, Feb. 1911.
7. PROFFIT, W. R. Contemporary Orthodontics. St. Louis: MosbyYear Book, 1999. p. 296-325.

8. REITAN, K. Clinical and histologic observations on tooth movement during and after orthodontic treatment. Am J Orthod, St. Louis, v. 53, no. 10, p. 721-745, Oct. 1967.

9. SCHWARZ, A. M. Tissue changes incident to orthodontic tooth movement. Int J Orthod, Milwaukee, v. 18, p. 331-352, 1932.

10. TWEED, C. H. Clinical Orthodontics. St Louis: C.V. Mosby, 1966. v. 1.

\section{Endereço para correspondência}

Milton Santamaria Jr.

Rua Prof. Lourenço Roselino, $n^{\circ} 630$ - Lagoinha

CEP: 14.095-170 - Ribeirão Preto/SP

E-mail: santamariajr@mailcity.com 